\title{
A note on location and the output effect of ad-valorem taxes under free entry oligopoly
}

\author{
Yeung-Nan Shieh* \\ ${ }^{1}$ Department of Economics, San Jose State University, USA
}

\begin{abstract}
This paper examines the output effect of an ad-valorem tax of undifferentiated oligopolistic firms in the Weber-Moses triangle. It shows that an increase in the ad-valorem tax will increase each firm's output but may increase the number of firms and total output of firms if the inverse demand function is linear, concave or not too convex. This result is different from the wellknown Tanaka's result in the non-spatial economy. It indicates that oligopolistic firm's location decision has important influence on the impact of the ad-valorem tax on the number of firms and total output of undifferentiated oligopoly.
\end{abstract}

Keywords: ad-valorem taxes, output and location, free entry undifferentiated oligopoly JEL Classification Codes: H25, L13, R38

\section{Introduction}

In his well-known paper, On the effects of commodity tax under free entry (1993), Tanaka investigated the effects of an ad-valorem tax on output per firm, the number of firms and total output of undifferentiated oligopolistic firms with free entry. Under the assumptions that (1) $\mathrm{N}$ identical firms produce a homogenous good and make Cournot-Nash conjectures about their rivals' production decisions; (2) firms are free to enter and leave the industry; (3) the sufficient second order conditions and the stability conditions are satisfied, Tanaka obtained the following remarkable result:

\footnotetext{
*E-mail: ynshieh@yahoo.com.

Citation: Shieh, Y-N (2015) A note on location and the output effect of ad-valorem taxes under free entry oligopoly, Economics and Business Letters, 4(1), 30-35.
} 
An increase in the ad-valorem commodity tax will increase output per firm, decrease the number of firms and decrease total output of oligopolistic firms if the inverse demand function is linear, concave or not too convex. (Tanaka, 1993, pp. 45-46).

This result is different from that of the specific tax case, Besley (1989). It is frequently cited in the formal study of public finance, trade and marketing science, e.g., Okuguchi and Yamazaki (1994), Ushio (2000), Allen, Eagle and Rose (2002). However, this result is based on the nonspatial setting in which resource providers, consumers and producers are settled at the oligopolistic firm's location and transportation costs are negligible. The real economy is characterized by a spatial dispersion of resource providers, consumers and producers over geographic space with trade among them always incurring transport costs. Thus, it would be interesting to examine the effects of an ad-valorem tax on output per firm, the number of firms and total output of undifferentiated oligopolistic firms in a spatial setting.

The purpose of this note is to fill this gap. It explicitly incorporates oligopolistic market structure into the familiar Weber-Moses triangular location model, Moses (1958), and examines the effects of an ad-valorem tax on output per firm, the number of firms and total output of firms. This model is identical to the model used by Shieh (2013) in which Shieh investigates the impact of an ad-valorem tax on the location decision of oligopolistic firm. In this note, we will use the same model to reexamine the well-known Tanaka proposition. It will be shown that the Tanaka proposition may not hold in the oligopolistic location model. Although our analysis is based on a simplified location model, it will shed some light on the output and location effects of the advalorem tax in a spatial economy.

\section{Output effect of an ad-valorem tax}

Following Mai and Hwang (1992) and Shieh (2013), we assume that $N$ firms employ two transportable inputs $m_{1}$ and $m_{2}$ located at $A$ and $B$ in Figure 1 to produce a homogenous product $(q)$ which is sold in the output market $C$. Each firm is interested in finding the optimum plant location E. In the figure, the distance $a$ and $b$ and the angle $\pi / 2>\gamma>0$ are given. Assume further that (1) the $\mathrm{N}$ firms are identical and symmetric; (2) they make Cournot-Nash conjectures about their rivals' production and location decisions; (3) the production function is homothetic. Thus, the profit-maximizing production-location decision of the representative firm can be formulated as:

$$
\max \Pi=[P(Q)-r h] q-C(q ; h, \theta)-t P(Q) q
$$

where $Q=\sum q$ is the market quantity demanded; $C(q ; h, \theta)=c\left(w_{1}+r_{l} z_{l}, w_{2}+r_{2} z_{2}\right) H(q), z_{l}=\left(a^{2}\right.$ $\left.+h^{2}-2 a h \cos \theta\right)^{1 / 2}, z_{2}=\left[b^{2}+h^{2}-2 b h \cos (\gamma-\theta)\right]^{1 / 2} ; w_{1}$ and $w_{2}$ are the base prices of $m_{1}$ and $m_{2}$ at their sources; $r, r_{1}$ and $r_{2}$ are constant transportation rates of $q, m_{1}, m_{2} ; z_{1}, z_{2}$, and $h$ are the distances from the plant location to two source location vertices: $A, B$ and the market location vertex: $C .{ }^{1} P(Q)$ is inverse demand function for output, $P_{Q} \equiv \partial P / \partial Q<0, P_{Q}+q P_{Q Q}<0$, Mai and Hwang $(1992$, p.256) $t=$ the ad-valorem tax rate, $l>t>0$. It should be noted that:

\footnotetext{
${ }^{1}$ Applying the constrained cost minimization analysis and using the property of homothetic production function, we can derive $C(q ; h, \theta)=c\left(w_{1}+r_{1} z_{1}, w_{2}+r_{2} z_{2}\right) H(q)$. For details, see Shieh $(2013, \mathrm{p} .8)$.
} 
$N$

$\sum$ denotes $\sum$, where $N=$ number of firms.

$i=1$

Figure 1. The Weber-Moses Triangle

C

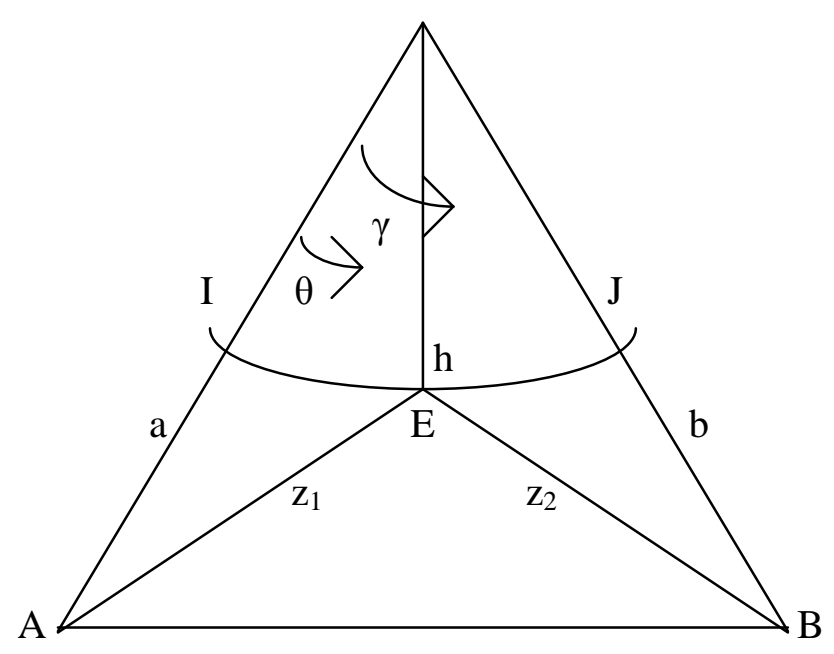

The first-order conditions for this profit maximization are derivable as follows:

$$
\begin{aligned}
& (\partial \Pi / \partial q)=(1-t)\left(P+P_{Q} q\right)-r h-c(\theta, h) H_{q}(q)=0 \\
& (\partial \Pi / \partial \theta)=-c_{\theta} H(q)=0 \\
& (\partial \Pi / \partial h)=-r q-c_{h} H(q)=0
\end{aligned}
$$

where $c_{\theta} \equiv \partial c(.) / \partial \theta, c_{h} \equiv \partial c(.) / \partial h$. If the entry and exit of firms is free, the zero profit condition determines the equilibrium number of firms endogenously.

$$
\Pi=[P(N q)-r h] q-c(.) H(q)-t P(N q) q=0
$$

If there is an interior solution, we can solve equations (2) - (5) for $q, \theta, h$ and $N$ in terms of $t$.

Next, we examine the effects of an ad-valorem tax under two different cases: (1) the plant location is predetermined and (2) the plant location is a decision variable.

\section{1. $\theta$ and $h$ are given}

In this case, the location variables $\theta$ and $h$ are held constant. Eqs (3) and (4) should be dropped. Applying the standard comparative static analysis, i.e., totally differentiating equations (2) and (5) and using Cramer's rule, we obtain:

$$
\begin{aligned}
& (\partial q / \partial t)_{\underline{\theta h}}=(1 / J)(1-t) q^{3} S \\
& (\partial N / \partial t)_{\underline{\theta h}}=(q / J)(1-t)\left[P\left(\left(P_{Q}+q P_{Q Q}\right)+\left\{P_{Q}-[1 /(1-\mathrm{t})] c(.) H_{q q}\right\}\right)-(N-1) q S\right] \\
& (\partial Q / \partial \underline{\mathrm{t}})_{\underline{\theta h}}=N(\partial q / \partial t)+q(\partial N / \partial t)=
\end{aligned}
$$




$$
\begin{aligned}
& \quad=\left(q^{2} / J\right)(1-t)\left(P\left\{P_{Q}-[1 /(1-\mathrm{t})] \mathrm{c}(.) H_{q q}\right\}+P_{Q}\left(P+q P_{Q}\right)\right) \\
& \mathrm{J}=\Pi_{\mathrm{qq}} \Pi_{\mathrm{N}}-\Pi_{\mathrm{qN}} \Pi_{\mathrm{q}}= \\
& =(1-t)^{2} q^{2} P_{Q}\left(\left(\mathrm{P}_{\mathrm{Q}}+q P_{Q Q}\right)+\left\{P_{Q}-[1 /(1-t)] \mathrm{c}(.) H_{q q}\right\}\right)
\end{aligned}
$$

where $\left(P+q P_{Q}\right)=$ marginal revenue $>0$ and $\mathrm{S}=\left(\mathrm{P}_{\mathrm{Q}}^{2}-\mathrm{PP}_{\mathrm{QQ}}\right)>0$ if the inverse demand function is linear $\left(P_{Q Q}=0\right)$, concave $\left(P_{Q Q}<0\right)$ or not too convex $\left[\left(P_{Q}^{2} / P\right)>P_{Q Q}>0\right]$. Assume that $\left(P_{Q}+q P_{Q Q}\right)<0, P_{Q}-[1 /(1-t)] c(.) H_{q q}<0$, (Seade 1980a, p. 483; Tanaka 1993, pp. 44-45) and $\Pi_{\mathrm{qq}}<0$ (Seade 1980b). Hence $\mathrm{J}>0$ and the stability conditions are met. ${ }^{2}$

Eqs (6)-(9) show that:

An increase in the ad-valorem tax will increase output per firm, decrease the number of firms and decrease total output of oligopolistic firms if the inverse demand function is linear, concave or not too convex.

This result is consistent with the Tanaka result in the non-spatial economy. It indicates the well-known Tanaka proposition can be applied to the spatial economy when the plant location is given.

\section{2. $\theta$ and $h$ are variables}

In this case, $\theta$ and $h$ are decision variables. Totally differentiating equations (2) - (5) and applying Cramer's rule, we obtain:

$$
\begin{aligned}
(\partial \theta / \partial t) & =\left(1 / D_{4}\right)(1-t) q^{3} \Pi_{\theta h} c_{h}\left\{[H(q) / q]-H_{q}\right\} S \\
(\partial h / \partial t) & =\left(-1 / D_{4}\right)(1-t) q^{3} \Pi_{\theta \theta} c_{h}\left\{[H(q) / q]-H_{q}\right\} S \\
(\partial q / \partial t) & =\left(D_{2} / D_{4}\right)(1-t) q^{3} S \\
(\partial N / \partial t) & =\left(q D_{2} / D_{4}\right)\left(\left\{(1-t)\left[P\left(\left(P_{Q}+q P_{Q Q}\right)+\left\{P_{Q}-[1 /(1-t)] c(.) H_{q q}\right\}\right)-(N-1) q S\right)\right]\right\} \\
- & \left.\left(1 / D_{2}\right) P \Pi_{\theta \theta} \Pi_{q h}{ }^{2}\right) \\
(\partial Q / \partial t) & =N(\partial q / \partial t)+q(\partial N / \partial t) \\
= & \left(q^{2} D_{2} / D_{4}\right)\left(\left\{(1-t)\left[P\left\{P_{Q}-[1 /(1-t)] c(.) H_{q q}\right\}+P_{Q}\left(P+q P_{Q}\right)\right]\right\}\right. \\
& -\left(1 / D_{2}\right)\left(P \Pi_{\theta \theta} \Pi_{q h}{ }^{2}\right)
\end{aligned}
$$

where $\Pi_{\theta h}=-c_{h \theta} H(q) ; \Pi_{\theta \theta}=-c_{\theta \theta} H(q) ; \Pi_{q h}=c_{h}\left\{[H(q) / q]-H_{q q}\right\} ; D_{2}=\Pi_{\theta \theta} \Pi_{h h}-\Pi_{\theta h}{ }^{2}$ and $D_{4}$ are the relevant Hessian determinant. It should be noted that $\Pi_{\theta \theta}\left\langle 0, D_{2}>0\right.$ and $D_{4}>0$ by the stability conditions (Dixit, 1986, p. 117). $c_{h}<0$ can be seen from equation (4) and $[H(q) / q]-H_{q}$ $>0$ is due to increasing returns to scale (for details see Hwang, Mai and Shieh (2007)).

It is clear that the sign of $(\partial q / \partial t)$ crucially depends upon the shape of market demand function. In the case where the inverse demand function is linear, concave or not too convex, i.e., $S>0$, from (12), we obtain $(\partial q / \partial t)>0$. In other words, an increase in the ad-valorem tax will increase output per firm.

\footnotetext{
${ }^{2}$ One referee suggests that we also examine the impact of ad-valorem taxes on final prices $(\partial P / \partial \mathrm{t})$ as most of tax incidence papers, for example, Delipalla and Keen (1992). Since our model involves location decisions in a heterogeneous cost space, it is much easy to see the impact of ad-valorem taxes on output and then plant location. We appreciate referee's valuable suggestion and will pursue this in our next project.
} 
Next, we turn to the effect of an increase in the ad-valorem tax on equilibrium number of undifferentiated oligopolistic firms. If $\mathrm{S}>0$, from Eq. (13), we can see the sign of $(\partial N / \partial t)$ can't be a priori determined because $(1-t)\left(\mathrm{P}\left\{\left(P_{Q}+P_{Q Q} q\right)+\left[(1 /(1-t)] c(.) H_{q q}\right]\right\}-(N-1) q S\right)<0$, and $\left(1 / \mathrm{D}_{2}\right) P \Pi_{\theta \theta} \Pi_{q h}{ }^{2}>0$. However, we can show

$$
\begin{aligned}
& (\partial N / \partial t)>(<) 0 \\
& \text { as } \left.-(1-t)\left[P\left(\left(P_{Q}+q P_{Q Q}\right)-\left\{P_{Q}-[1 /(1-\mathrm{t})] c(.) H_{q q}\right\}\right)-(N-1) q S\right)\right]<(>)-\left(1 / \mathrm{D}_{2}\right) P \Pi_{\theta \theta} \Pi_{q h}{ }^{2}
\end{aligned}
$$

In other words, an increase in the ad-valorem tax may increase the number of undifferentiated firms even if the inverse demand function is linear, concave or not too convex, i.e., $S>0$.

This result is different from that of Tanaka (1993). In the non-spatial setting, the demand effect, $\left.(1-t)\left[\left(P\left\{\left(P_{Q}+P_{Q Q} q\right)+\left[(1 /(1-t)] c(.) H_{q q}\right]\right\}\right)-(N-1) q S\right)\right]<0$, thus $(\partial N / \partial t)_{\theta h}<0$. In the Weber-Moses triangle, if $S>0$, then $(\partial q / \partial t)>0$ and $(\partial h / \partial t)<0$. The oligopolistic firm will move its plant location closer to the CBD and save transportation costs. If this location effect, $P\left(\Pi_{\theta \theta} \Pi_{q h}{ }^{2}\right) / D_{2}>0$, dominates the demand effect. The firm's economic profit rises and new firms will enter. Thus, the number of firms will increase, i.e., $(\partial N / \partial t)>0$.

Finally, we consider the effect of an increase in the ad-valorem tax on total output of oligopoly. From Eq. (14), we obtain:

$$
\begin{aligned}
& (\partial Q / \partial t)>(<) 0 \\
& \text { as }-(1-t)\left[P\left\{P_{Q}-[1 /(1-\mathrm{t})] c(.) H_{q q}\right\}+P_{Q}\left(P+q P_{Q}\right)\right]<(>)-\left(1 / D_{2}\right) P \Pi_{\theta \theta} \Pi_{q h}{ }^{2}
\end{aligned}
$$

In other words, an increase in the ad-valorem tax may increase total output of oligopolistic firms. This result is also different from that of Tanaka (1993). In the non-spatial setting, the demand effect, $(1-t)\left[P\left\{P_{Q}-[1 /(1-t)] c(.) H_{q q}\right\}+P_{Q}\left(P+q P_{Q}\right)\right]<0$, thus $(\partial Q / \partial t)_{\underline{\theta h}}<0$. In the Weber-Moses triangle, if $S>0$, then $(\partial q / \partial t)>0$ and $(\partial h / \partial t)<0$. An increase in the ad-valorem tax will move the firm's location closer to the CBD and save transportation costs. When the economic profit rises, new firms will enter and total output will increase.

\section{Concluding remarks}

We have examined the effects of an ad-valorem tax on output per firm, the number of firms and total output of undifferentiated oligopolistic firms in the Weber-Moses triangle. In the case where the market demand function is linear, concave or not too convex, we show that an increase in the ad-valorem tax will cause each firm's output to raise and move the plant location close to CBD. This result indicates Tanaka's proposition that an increase in an ad-valorem tax will increase output per firm holds in the spatial setting. We further demonstrate that an increase in the advalorem tax will increase the number of firms and total output of firms if the location effect dominates the demand effect. This result is different from Tanaka's result in the non-spatial economy. Our investigation shows that the location decision has very important influence on the impact of the ad-valorem tax on total output and the number of firms of undifferentiated oligopoly with free entry.

Acknowledgements. I am grateful to three anonymous referees for their valuable comments and suggestions. I also like to thank Professor X. Henery Wang for helpful comments at an earlier stage of this research. Any remaining errors are mine. 


\section{References}

Allen, L., Eagle, L. and Rose, L. (2002) Economic implications of a tax on TV advertising: the New Zealand case, Market Bulletin, 13, article 2, 1-12.

Besley, T. (1989) Commodity taxation and imperfect competition: a note on the effect of entry, Journal of Public Economics, 40(3), 359-367.

Delipalla, S. and Keen, M. (1992) The comparison between ad valorem and specific taxation under imperfect competition, Journal of Public Economics, 49(3), 351-367.

Dixit, A.K. (1986) Comparative statistic for oligopoly, International Economic Review, 27(1), 107-122.

Hwang, H., Mai, C.C. and Shieh, Y.N. (2007) Production-location decision and free entry oligopoly: a correction, Journal of Urban Economics, 61(3), 576-579.

Mai, C.C. and Hwang, H. (1992) Production-location decision and free entry oligopoly, Journal of Urban Economics, 31(2), 252-271.

Moses, L.N. (1958) Location and the theory of production, Quarterly Journal of Economics, 72(2), 259-272.

Okugnchi, K. and Yamazaki, T. (1994) Ad-valorem and specific taxes and optimal Pigouvian tax within Cournot oligopoly, Keio Economic Studies, 31(2), 25-32.

Seade, J. (1980a) On the effect of entry, Econometrica, 48(2), 479-489.

Seade, J. (1980b) The stability of Cournot revisited, Journal of Economic Theory, 23(1), 15-27.

Shieh, Y.N. (2013) Effects of ad-valorem taxes on location decision under free entry Cournot oligopoly, Economics and Business Letters, 2(1), 5-12.

Tanaka, Y. (1993) On the effects of commodity tax under free entry, Keio Economic Studies, 30(1), 43-52.

Ushio, Y. (2000) Welfare effects of commodity taxation in Cournot oligopoly, Japanese Economic Review, 51(2), 268-273. 